Semin Nephrol. 2018 November ; 38(6): 618-628. doi:10.1016/j.semnephrol.2018.08.006.

\title{
Oral Anticoagulation in Patients with End-stage Kidney Disease on Dialysis and Atrial Fibrillation
}

\author{
Austin $\mathrm{Hu}$, Jingbo Niu, and Wolfgang C Winkelmayer ${ }^{*}$ \\ Section of Nephrology, Department of Medicine, Baylor College of Medicine, Houston, Texas
}

\author{
Keywords \\ Hemodialysis; Peritoneal Dialysis; Arrhythmia; Outcomes; Drug Safety
}

\section{Introduction}

Atrial fibrillation (AF) is the most common sustained arrhythmia, and has been estimated to affect anywhere from 2.7 to 6.1 million American adults in $2010^{1}$ and more than 33 million individuals world-wide. ${ }^{2}$ Patients with AF are at increased risk of several adverse outcomes and have overall increased mortality. Thromboembolic events are well-known complications of AF, particularly ischemic stroke, whose risk was 4 to 5-fold in patients with AF compared to those in sinus rhythm. ${ }^{1}$ The risk of ischemic stroke can be substantially decreased by oral anticoagulation in appropriate patients and, thus, is a Class I recommendation according to the 2014 AHA/ACC/HRS Guidelines. ${ }^{3}$ Specifically, these guidelines recommend that oral anticoagulation be used in patients with $\mathrm{AF}$ and certain stroke risk factors summarized in a $\mathrm{CHA}_{2} \mathrm{DS}_{2}$-VAsc score of 2 or greater. ${ }^{3}$ Vitamin $\mathrm{K}$ antagonists (VKA) such as warfarin have been traditionally used for stroke prevention in patients with $\mathrm{AF}$, where they had been found to substantially reduce the risk of any stroke both compared with placebo or no treatment as well as when compared with antiplatelet therapy. ${ }^{4}$ However, VKAs have several important drawbacks including an increased risk of bleeding, a narrow therapeutic window, being nontarget specific, the need for frequent international normalized ratio (INR) monitoring, and numerous food and drug interactions. ${ }^{5}$

More recently, a number of new medications addressing some of these shortfalls have been developed and brought to market. Commonly referred to as novel or direct oral anticoagulants (DOAC), this newer generation of oral anticoagulants includes the direct thrombin (factor II) inhibitor, dabigatran, as well as the factor Xa inhibitors, rivaroxaban, apixaban, and edoxaban. All of these drugs were tested in large activecomparator trials compared to vitamin $\mathrm{K}$ antagonist treatment for stroke prevention in patients with $\mathrm{AF}$ and demonstrated to be non-inferior or even superior to active control vitamin $\mathrm{K}$ antagonism

\footnotetext{
*Correspondence to. Section of Nephrology, Baylor College of Medicine, One Baylor Plaza, Suite ABBR, R705, MS: 395; Houston, Texas 77030. winkelma@bcm.edu.

Publisher's Disclaimer: This is a PDF file of an unedited manuscript that has been accepted for publication. As a service to our customers we are providing this early version of the manuscript. The manuscript will undergo copyediting, typesetting, and review of the resulting proof before it is published in its final citable form. Please note that during the production process errors may be discovered which could affect the content, and all legal disclaimers that apply to the journal pertain.
} 
treatment at stroke prevention while having similar if not decreased risks of bleeding. ${ }^{6-9}$ These new medications have important advantages over warfarin in that they do not require frequent coagulation monitoring and have fewer food and drug interactions; however, some of their disadvantages include high cost and approved use only in non-valvular AF as well as, until recently, limited options to antagonize them in case of major bleeding or emergency surgery. ${ }^{3,10}$

\section{Atrial Fibrillation in End-Stage Kidney Disease}

Both the prevalence and the incidence of AF are increased in patients with chronic kidney disease (CKD), both among those with lower estimated glomerular filtration rate and, independently, those with higher proteinuria. ${ }^{11-13}$ Many of the same diseases or conditions (e.g., diabetes, hypertension), risk factors, and pathological processes that increase the risk for AF can also lead or contribute to the development of chronic kidney disease (CKD) and accelerate its progression to end-stage kidney disease (ESKD) [Figure 1]. ${ }^{14}$ Interestingly, the converse has also been shown in that $\mathrm{AF}$ was found to be associated with new onset $\mathrm{CKD}^{15}$ as well as progression of CKD to ESKD. ${ }^{16,17}$

These patients with CKD are also at increased risks for stroke $\mathrm{e}^{18}$ and, based on these associations, some have even argued that since kidney dysfunction was a potent predictor for stoke and systemic embolism it should be included in stroke riskstratification criteria $\left(\mathrm{R}_{2} \mathrm{CHADS}_{2}\right) \cdot{ }^{18}$

Thus, it is not surprising that the incidence and prevalence of AF are particularly high in patients with ESKD requiring maintenance dialysis. ${ }^{13,19}$ The incidence of AF in older Medicare-insured patients on hemodialysis, in particular, was estimated at 148 per 1000 person-years. ${ }^{20}$ However, many of these studies arrived at these estimates by ascertaining AF from insurance claims or electronic health records. Recent studies using implantable loop recorders have indicated that AF may be even more common, perhaps near $40 \%$, in patients with ESKD on $\mathrm{HD},{ }^{21}$ although the study populations may not have been representative of the general population.

Patients with ESKD are at much increased risk of ischemic stroke compared with the general population, ${ }^{22}$ and AF confers a significantly higher risk of ischemic stroke in patients with ESKD compared with otherwise similar patients without AF. ${ }^{23,24}$ Thus, one could reasonably think that patients with ESKD and AF would be a good target population to consider anticoagulation for embolic prophylaxis. However, patients with ESKD - even absent oral anticoagulation - are also at much increased risk of bleeding, including intracranial hemorrhage, gastrointestinal bleeding, and bleeding from dialysis access sites. 22,25 Thus, it is not immediately clear whether oral anticoagulation in patients with ESKD and AF would be similarly net beneficial compared with the more general population with AF.

\section{Oral anticoagulation for AF in ESKD}

Indeed, there is a lack of top-level evidence for the effectiveness and safety of warfarin for stroke prophylaxis in patients with ESKD and AF, and the existing observational studies show no clear and consistent benefit and even possible harm. ${ }^{26}$ 
The guidance statements issued by professional organizations are mixed as well. The 2014 AHA/ACC/HRS Guidelines gives a Class IIa indication to prescribe warfarin for ESKD patients with $\mathrm{AF}$ and a $\mathrm{CHAD}_{2} \mathrm{DS}_{2}$-VASc score $22^{3}$ while experts convened by the leading international guideline group in nephrology, Kidney Disease: Improving Global Outcomes (KDIGO), do not recommend routinely initiating anticoagulation for embolic protection in the ESKD population. ${ }^{27}$ In clinical practice, only small proportions ( 15-40\%) of patients with ESKD on dialysis who have AF receive VKA. ${ }^{28-30}$ It has further been shown that these patients spend the majority of their time outside of the recommended therapeutic range and long-term persistence with newly initiated VKA treatment is poor ( $\sim 30 \%$ at 1 year). ${ }^{30,31}$

The same paucity of top-level evidence also exists regarding DOAC use in ESKD patients with $\mathrm{AF}$ as these patients were systematically excluded from the large-scale randomized controlled trials that led to the initial U.S. Food and Drug Administration (FDA) approval of these agents ${ }^{6-9}$ and it was not until 2014 that these drugs started receiving FDA approvals or, rather, labeled dosing guidance for use in ESKD patients ${ }^{32,33}$ based off of rather limited pharmacokinetic and pharmacodynamic studies. ${ }^{34-36}$ Yet, recent observational studies have reported DOACs are increasingly being used "off-label" in these patients even before official FDA approval for use in this population. ${ }^{37-39}$ However, more recent prescribing patterns of oral anticoagulants, especially DOACs are not well understood.

Current Practice in the U.S. Dialysis Population-We used the comprehensive registry of persons with ESKD in the U.S., the U.S. Renal Data System, to obtain a snapshot of prescribing behavior related to oral anticoagulation in patients with ESKD using data supplied in the 2017 USRDS Standard Analytical Files, spanning information up to $12 / 31 / 2015$. We specifically investigated the prevalence of any oral anticoagulant use, and of individual agents, in the second half of 2015 among ESKD patients covered by Medicare (Parts A, B, and D) who were previously diagnosed with AF. We also described the incidence of new initiation of oral anticoagulant therapy among patients previously not receiving any such treatment or new initiation of specific agents, whether completely new initiations or switches from other specific agents.

Among 216,847 patients on hemodialysis (HD) and 19,710 patients on peritoneal dialysis (PD) point prevalent on 7/1/2015, 78,689 (36.3\%) and 4583 (23.3\%) had previously been diagnosed with AF, respectively. Figure 2 shows the proportion of patients with AF who received any oral anticoagulation, or individual agents, separately for patients undergoing HD and PD.

Among those with AF, the proportions of patients on HD and PD receiving any oral anticoagulant were $27.4 \%$ and $28.8 \%$, respectively. On HD, $23.6 \%$ received warfarin and $3.5 \%$ received apixaban, with very few patients receiving dabigatran or rivaroxaban. The proportions were similar among those on $\mathrm{PD}$, with $25.1 \%$ receiving warfarin and $3.4 \%$ receiving apixaban. However, investigating patterns of new use of any single oral anticoagulant (among dialysis patients who had not filled any prescriptions for the same anticoagulant in the previous 6 months), 63.8\% initiated new treatment with warfarin whereas $34.5 \%$ did so using apixaban (Figure 3). Neither dabigatran, nor rivaroxaban was used much; not a single patient used edoxaban. Of those patients initiating warfarin, $96.3 \%$ 
were „true "e new users, whereas the remaining 3.7\% switched from a DOAC. By contrast, among new users of apixaban, $28.8 \%$ switched from warfarin, whereas $69.6 \%$ appeared to be truly new initiators of oral anticoagulation.

The results from this snapshot of oral anticoagulant use in the second half of 2015 motivate a closer look at some of the evidence related to each anticoagulant, and specific treatment considerations especially as they relate to patients with ESKD.

\section{Warfarin}

Warfarin was the most commonly used oral anticoagulant in the USRDS in the second half of 2015 with a period prevalence of $\sim 25 \%$ in both the HD and PD populations, which far surpassed the prevalence of each of the other oral anticoagulants which jointly were used in $<4 \%$ of these patients. This is not surprising for multiple reasons: First, there is a pharmacologic basis supporting its use in ESKD patients as warfarin is mainly metabolized in the liver and not eliminated by the kidneys. Warfarin is also mostly bound to plasma protein so its anticoagulation efficacy is not significantly altered by dialysis. ${ }^{39}$ Second, even though there is no top level evidence for warfarin use in ESKD patients with AF, since the large Phase 3 trials for the DOACs all systematically excluded ESKD patients with $\mathrm{AF}^{6-9}$ warfarin was the only oral anticoagulant recommended (" $[\ldots]$ it is reasonable to prescribe warfarin [...]") by the 2014 AHA/ACC/HRS guidelines for thromboembolic prophylaxis if their $\mathrm{CHAD}_{2} \mathrm{DS}_{2}$-VASc score was $\geq 2 .{ }^{3}$ This is likely due to its clinical familiarity to providers and its "[...] acceptable risks of hemorrhage [...]."3 Indeed, a large majority of ESKD patients with AF generally have $\mathrm{CHAD}_{2} \mathrm{DS}_{2}$-VASc scores 22 . In a national Danish study, of 1142 patients on dialysis evaluated, 898 (78.6\%) patients had a $\mathrm{CHAD}_{2} \mathrm{DS}_{2}$-VASc score $\geq 2 .{ }^{40}$ According to guidelines, these patients should be considered for antithrombotic therapy. ${ }^{3}$

However, in contrast to the commonality of this standard indication, it is remarkable to note that only a small fraction of patients with ESKD receive warfarin across various countries, previous reports once again supported by the latest findings in USRDS data where $<24 \%$ of patients received warfarin. This practice pattern highlights the underlying reservations and fears providers may have for starting or continuing anticoagulation in this vulnerable population. The most obvious complication of warfarin is bleeding and patients with ESKD already have a high baseline risk for bleeding. A Japanese study found that ESKD patients on dialysis had a ten-fold relative-risk increase for cerebral hemorrhage compared to controls ${ }^{41}$ and another study demonstrated increased incidences of GI bleeding in ESKD patients compared to the general population. ${ }^{42}$ In a retrospective observational study, Phelan et al. found that patients on HD taking warfarin were more prone to bleeding than nondialysis patients on warfarin but did not detect a significant difference in major bleeding rates between dialysis patients receiving and not receiving warfarin, further suggesting that ESKD itself is a major risk factor for bleeding. ${ }^{43}$

The reasons for increased bleeding in this patient population are numerous. Firstly, these patients have multiple pathophysiological mechanisms that increase bleeding risk including impairment in platelet function and the coagulation cascade. ${ }^{44}$ In addition to derangements 
in hemostasis, patients with ESKD on dialysis tend to have other risk factors that increase their risk for bleeding including older age, ${ }^{45}$ increased frailty, ${ }^{46,47}$ increased falls, ${ }^{48}$ and increased risk for fractures ${ }^{49}$ factors that may sway a clinician away from initiating warfarin for thromboembolic prophylaxis in $\mathrm{AF} .{ }^{50}$ Finally, the use of heparin during hemodialysis is not routinely stopped for patients taking oral anticoagulants, which may further increase their risk for bleeding.

Thus, when these patients are initiated on warfarin, several observational studies show they have higher rates of adverse bleeding events ${ }^{29}$ including increased rates of cerebral hemorrhage and hemorrhagic stroke compared to non-warfarin using controls. ${ }^{30,51,52}$ although this was not shown in every observational study (Table 1). ${ }^{43,53}$ These differences may be in part due to sample size, patient factors, and INR control, and all studies are limitated by an observational design. Nevertheless, studies do show that therapeutic INR control is more challenging and the time in therapeutic range (TTR) lower in patients with ESKD due to multiple reasons ${ }^{31,43,54}$ and may contribute to higher rates of bleeding in this patient population. ${ }^{54}$ For instance, Yang et al. found that patients on dialysis had a TTR of $42.4 \%$ while patients an eGFR of $60-90$ had a TTR of $60.1 \% .^{31}$

In addition, it is important to note that warfarin is associated with several adverse nonbleeding side effects as well. Warfarin interferes with the vitamin K-dependent gammaglutamyl carboxylase enzyme that is required for the activation of matrix G1a protein (MGP). ${ }^{5}$ MGP inhibits vascular calcification and studies in animals and humans have demonstrated accelerated vascular or valvular calcification when MGP activity is impaired, 55 which may explain, in part, why some studies showed an increase in the risks of ischemic stroke with warfarin. ${ }^{52,56}$ Similarly, warfarin is also a risk factor for developing calciphylaxis, a rare yet highly morbid skin lesion with calcium deposition in the arteries and tissue, which can predispose the patient to severe infections with high rates of mortality. ${ }^{57}$ Finally, it has been recently demonstrated that warfarin can induce micro-glomerular bleeds with subsequent red blood cell - induced tubular obstruction and renal injury, a condition known as warfarin-related nephropathy. ${ }^{58}$ This may be important even in patients on dialysis as preservation of any residual renal function may confer a benefit in mortality. ${ }^{59}$

Still, these bleeding and non-bleeding risks may still be worth incurring if the benefits in terms of reduction of thromboembolic events are sufficiently large. However, the premise that warfarin therapy in ESKD patients would reduce the rates of ischemic stroke is actually not supported absent any top-level evidence from randomized trials, and the available observational evidence regarding warfarin for thromboembolic prophylaxis in ESKD patients is conflicting at best. ${ }^{60}$ Some studies showed clinical benefit with reduction in ischemic strokes, ${ }^{30,40,43,53}$ others showed no clear reduction in ischemic strokes, ${ }^{29,43,51,61}$ while again other studies showed an increased risk for ischemic stroke in the overall study population ${ }^{52}$ or all types of stroke in patients $>75$ years old (Table 1) ${ }^{56}$ It is important to note that some of the studies that did not demonstrate a clear benefit of ischemic stroke with warfarin found increased rates of bleeding with warfarin, with the overall conclusion that warfarin is associated with net clinical harm in patients with ESKD (Table 1). ${ }^{29,51}$ Four recent large meta-analyses pooling several of the different observational studies also came to the same conclusion that there was no significant association with warfarin and reduced rates 
of ischemic stroke but a saw a significant association between warfarin and increased bleeding rates. ${ }^{62-65}$ Unfortunately, all of the studies have varying degrees of heterogeneity such as the number of patients studied, patient characteristics, and follow-up time, as well as substantially different study designs (prevalent versus incident AF; warfarin naïve patients versus new users); and, importantly, they are all prone to bias and confounding due to their observational nature. Thus, there is a strong need for high-quality randomized placebocontrolled trials to assess the benefits and risks of warfarin in this high-risk patient population. Until then, the decision to use warfarin for thromboembolic prophylaxis in ESKD patients must be tailored to each individual with careful consideration of their risk factors for thromboembolism and bleeding.

\section{Dabigatran}

Dabigatran is a direct thrombin inhibitor and received FDA approval in late $2010^{66}$ after the Randomized Evaluation of Long-Term Anticoagulation Therapy (RE-LY) study showed that dabigatran had equal or better thromboembolic protection than warfarin and had less or equal bleeding events compared to warfarin depending on the dosage used, although patients with a creatinine clearance $(\mathrm{CrCl})<30 \mathrm{~mL} /$ minute were excluded from this trial. ${ }^{6}$ Nevertheless, previous findings have indicated that starting in 2010, dabigatran was used in ESKD patients with AF, de novo use in some, while others were being switched to dabigatran from warfarin, likely due to the risks of warfarin use in ESKD. However, dabigtran use was rather small overall with it being used in only $<0.1 \%$ of the US ESKD population in mid-to-end 2015, making it the least commonly used among the oral anticoagulants studied. The reasons for this are probably multi-factorial, but one likely reason of dabigatran"s low use is because the pharmacokinetic and pharmacodynamic profile of dabigatran makes it unfavorable to be used in patients with ESKD. Dabigatran is mainly eliminated by the kidneys ( $80 \%$ ), and the least protein bound among DOACs, and increasing severity of renal impairment leads to increasing levels of drug accumulation as indirectly measured by the aPTT. ${ }^{66}$ A secondary analysis of the RE-LY study analyzing stroke and bleeding rates in different creatinine clearance subgroups found increasing rates of bleeding with declining creatinine clearance in both dabigatran and warfarin. However, bleeding rates for dabigatran increased at a faster rate compared to warfarin with declining kidney function and dabigatran ${ }^{\text {ee }} \mathrm{s}$ advantage over warfarin in terms of bleeding rates was lost in patients with a $\mathrm{CrCl}<50 \mathrm{ml} /$ minute. ${ }^{67}$ In patients with ESKD, dabigatran use was found in one study to be even more unsafe than warfarin with significantly more adverse bleeding events. $^{38}$

Due to increased bleeding risks with kidney impairment, dabigatran is supposed to be dosereduced to $75 \mathrm{mg}$ twice a day for patients with a $\mathrm{CrCl}$ between 15 and $30 \mathrm{ml} / \mathrm{min}$ per FDA dosing guidelines and it has not (yet) been FDA approved for use in ESKD patients (Table 2). ${ }^{66}$ Yet, it is interesting to note that in an earlier study it was found that approximately twothirds of the patients initiating dabigatran were started on the full dose regimen (150mg twice daily). ${ }^{37}$ This may be due to lack of provider awareness and the paucity of top-level data on the safety and efficacy of dabigatran use in ESKD patients. However, dabigatran use in ESKD patients poses yet another concern. Dabigatran is the least protein bound out of all the oral anticoagulants and up to $60 \%$ of dabigatran can be cleared in a 4-hour HD session, 
potentially increasing the risk of thromboembolic events in those receiving dialysis regularly and increasing the risk of bleeding if a patient misses a dialysis session. ${ }^{39}$ Finally, there is early evidence to suggest dabigatran may also cause glomerular injury in a similar fashion to warfarin-related nephropathy. ${ }^{68}$

\section{Rivaroxaban}

Rivaroxaban is a factor Xa inhibitor and entered into the market in $2011^{33}$ based on the Rivaroxaban Once Daily Oral Direct Factor Xa Inhibition Compared with Vitamin K Antagonism for Prevention of Stroke and Embolism Trial in Atrial Fibrillation (ROCKET$\mathrm{AF})$ that showed non-inferiority of rivaroxaban in stroke prevention and overall clinically relevant bleeding rates compared to warfarin. ${ }^{7}$ Again, patients with $\mathrm{CrCl}<30 \mathrm{ml} / \mathrm{min}$ were excluded from the trial. However, just as with dabigatran, current USRDS data as well as previous research $^{38}$ show that patients with ESKD were treated with rivaroxaban after it was approved despite little data for its efficacy and safety in this population. Overall rivaroxaban use was low during the second half of 2015 with a period prevalence of $\sim 0.2 \%$ of patients on $\mathrm{HD}$ or $\mathrm{PD}$, but was used more than dabigatran.

There are certain properties that may make rivaroxaban more attractive an oral anticoagulant to use in the dialysis population than dabigatran. Aside from rivaroxaban "s daily dosing advantage over dabigatran "s twice a day dosing, rivaroxaban "s pharmacokinetic and pharmacodynamic profile is also more favorable for use in ESKD patients compared to dabigatran. Approximately one-third of rivaroxaban is eliminated by the kidneys while the rest is metabolized by the liver ${ }^{69}$ and rivaroxaban is minimally removed by dialysis. ${ }^{34}$ In the ROCKET-AF trial, patients with a creatinine clearance of 30 to $49 \mathrm{ml} /$ minute were given a dose-reduced $15 \mathrm{mg}$ dose from $20 \mathrm{mg}$; sub-group analysis of this group with moderate renal impairment revealed similar rates of stroke and systemic embolism as well as rates of major bleeding compared to warfarin, although it was not sufficiently powered to demonstrate meaningful statistical noninferiority or statistical superiority. ${ }^{70}$ While there are currently no randomized-controlled trials comparing the efficacy and safety of rivaroxaban and warfarin in patients with ESKD, small pharmacokinetic and pharmacodynamic studies have found that reduced of doses of $10 \mathrm{mg}$ in ESKD patients yielded similar levels as compared to the $20 \mathrm{mg}$ dose in healthy individuals, ${ }^{34}$ and a $15 \mathrm{mg}$ dose in ESKD patients led to similar drug levels in patients with moderate and severe CKD. ${ }^{71}$ This led the FDA to approve a revised label, released on 8/17/2016, in which the $15 \mathrm{mg}$ dose was indicated for use in ESKD patients (Table 2). ${ }^{33}$ One observational study did show that ESKD patients taking rivaroxaban had a 38\% higher risk for major bleeding and a 58\% increased risk for fatal bleeding compared to warfarin, although the risk of bleeding for dabigatran was even higher at $48 \% .{ }^{38}$ However, this could be confounded by the fact that roughly one-third of the studied patients on rivaroxaban took the regular $20 \mathrm{mg}$ dose, which may account for the majority of the observed $38 \%$ increase in bleeding risk as compared to warfarin. Patients bleeding from rivaroxaban also did not have a reversal agent available when the study was conducted which may explain why there was an even higher observed risk for fatal-bleeding in ESKD patients as compared with warfarin. ${ }^{38}$ This, however, may soon no longer be the case as andexanet alfa, a reversal agent for factor Xa inhibitors, was just recently approved by the FDA in 2018. ${ }^{10}$ 


\section{Apixaban}

Apixaban is another factor Xa inhibitor and received FDA approval in $2012^{32}$ when the Apixaban for Reduction in Stroke and Other Thromboembolic Events in Atiral Fibrillation (ARISTOTLE) trial showed superiority over warfarin in preventing the composite of ischemic or hemorrhagic stroke or systemic embolism and significantly lower rates of bleeding. ${ }^{8}$ The study had a provision to reduce the dose to $2.5 \mathrm{mg}$ twice daily when the patient had a serum creatinine concentration $(\mathrm{Cr})$ of $1.5 \mathrm{mg} / \mathrm{dL}$ or higher and was older than 80 years of age or weighed less than $60 \mathrm{~kg}$. However, the enrollment criteria still specified that patients with a $\mathrm{Cr}$ of $>2.5 \mathrm{mg} / \mathrm{dL}$ or $\mathrm{CrCl}<25 \mathrm{ml} / \mathrm{min}$ be excluded. Despite this, apixaban is being prescribed to patients with ESKD on dialysis and the period prevalence of its use was much higher than that of rivaroxaban and dabigatran: in the second half of 2015, $\sim 3.5 \%$ of patients with AF on HD or PD filled a prescription for apixaban.

Compared with the other DOACs, apixaban is the least reliant on kidney function for clearance as only $25 \%$ of the drug is eliminated by the kidneys. It is also minimally affected by dialysis in that a 4-hour dialysis session (Optiflux F180NR dialyzer, dialysate flow rate of $500 \mathrm{ml} / \mathrm{min}$, blood flow rate 350 to $500 \mathrm{ml} / \mathrm{min}$ ) will only remove $6.7 \%$ of the drug. ${ }^{36}$ While there is no top-level evidence on the efficacy and safety of apixaban in patients with ESKD, sub-analyses of two large randomized trials demonstrate apixaban" s safey and efficacy from mild to severe chronic kidney disease down to a $\mathrm{CrCl}$ of $25 \mathrm{ml} / \mathrm{min} .{ }^{72,73}$ Post-hoc analysis of the ARISTOTLE trial showed in patients with chronic kidney disease that the composite of ischemic and hemorrhagic stroke as well as systemic embolism was lower in the apixaban group than the warfarin-treated group although the findings were not statistically significant. Yet, bleeding complications were significantly lower in the apixaban arm than the warfarin arm, with the greatest benefit discrepancy seen in patients with more advanced CKD. ${ }^{72}$ In another trial comparing apixaban and aspirin in patients who failed VKA, sub-analysis showed that patients with AF and CKD with a $\mathrm{CrCl}>25 \mathrm{ml} / \mathrm{min}$ and $<80 \mathrm{ml} / \mathrm{min}$ had superior outcomes with apixaban compared to aspirin for stroke prevention while having similar bleeding rates. ${ }^{73} \mathrm{~A}$ small pharmacokinetic/pharmacodynamic study of apixaban in patients with ESKD showed that a single $5 \mathrm{mg}$ dose of apixaban resulted in an area under the curve that was $36 \%$ more than in healthy controls and that it was well tolerated among the subjects. Based on this pharmacological study, the FDA approved an amended label to endorse the use of the $5 \mathrm{mg}$ dose, twice daily, for ESKD patients with the alternate $2.5 \mathrm{mg}$ dose if their age was 80 or greater or if their weight was $60 \mathrm{~kg}$ or less (Table 2). ${ }^{32,36}$

This addition to the FDA label came in January of 2014, which may have further accelerated the use of apixaban in ESKD patients as observed in our study, although apixaban use amongst ESKD patients on dialysis was already rising prior to the FDA approved amendment. ${ }^{39}$ Yet, the optimal apixaban dose in ESKD patients still needs further study as Mavrakanas et al found that twice a day dosing of $2.5 \mathrm{mg}$ of apixaban over eight days in ESKD patients on HD resulted in similar drug levels relative to those observed in healthy controls whereas $5 \mathrm{mg}$ twice a day dosing led to potentially supratherapeutic levels in the same patients. ${ }^{74}$ While apixaban seems to be evolving as the main alternative to warfarin in patients with ESKD on dialysis and AF, efforts are underway to establish the highest-level evidence through several randomized trials that are ongoing or in the planning stage. The 
U.S.-based (RENAL-AF) trial randomizes patients with AF on dialysis to warfarin versus apixaban $5 \mathrm{mg}$ twice daily (with dose adjustment for low weight or old age per label) and is powered for non-inferiority for major bleeding (ClinicalTrials.gov identifier

NCT02942407); in Germany the otherwise similar (AXADIA) trial compares warfarin with apixaban $2.5 \mathrm{mg}$ twice daily (ClinicalTrials.gov identifier NCT02933697).

\section{Edoxaban}

Edoxaban is currently the latest Factor Xa inhibitor indicated for patients with non-valvular AF and was approved by the FDA in January $2015 .^{75}$ The Phase III trial, Effective Anticoagulation with Factor Xa Next Generation in Atrial FibrillationThrombolysis in Myocardial Infraction 48 (ENGAGE-AF TIMI 48), demonstrated that edoxaban was noninferior to warfarin at preventing strokes or systemic embolism while establishing edoxaban "s superiority over warfarin in terms of bleeding rates and reducing cardiovascular mortality. Similar to apixaban, the edoxaban trial also made a provision to decrease the dose by half if the $\mathrm{CrCl}$ was between 30 and $50 \mathrm{ml} / \mathrm{min}$, body weight was $<60 \mathrm{~kg}$, or if the patient was concurrently taking a strong P-glycoprotein inhibitor. ${ }^{9}$ In step with the other preexisting Phase III trials for DOACs, the ENGAGE-AF TIMI 48 trial also excluded patients with a $\mathrm{CrCl}<30 \mathrm{ml} / \mathrm{min}$.

Renal elimination of edoxaban is roughly $50 \%$ of the dose so renal impairment can result in increasing drug concentrations. In a pharmacological study, edoxaban use in patients with impaired kidney function resulted in a 32\%,74\%, and $72 \%$ higher exposure of edoxaban in mild $(\mathrm{CrCl}$ between 50 and $80 \mathrm{ml} / \mathrm{min})$, moderate $(\mathrm{CrCl}$ between 30 and $50 \mathrm{ml} / \mathrm{min})$, and severe kidney disease $(\mathrm{CrCl}<30 \mathrm{~min} / \mathrm{min})$ respectively compared to healthy controls. ${ }^{76}$ It is interesting to note the similarity of edoxaban concentrations observed in patients with moderate and severe kidney impairment, suggesting that edoxaban concentrations plateau after a certain point despite worsening kidney function due to edoxaban removal via other pathways. Clearly, more rigorous studies are needed to further define dosing strategies in ESKD patients. One smallscale pharmacological study did show that a $15 \mathrm{mg}$ dose was well tolerated in a small group of 10 patients with ESKD on HD, and that dialysis (F180NR, blood flow rate $350 \mathrm{ml} / \mathrm{min}$, dialysate flow rate $500 \mathrm{ml} / \mathrm{min}$ ) did not result in significant edoxaban removal. ${ }^{77}$ On an opposite note, pharmacokinetic data shows that patients with an estimated $\mathrm{CrCl}>95 \mathrm{ml} / \mathrm{min}$ had lower plasma levels of edoxaban and were found to have significantly higher rates of ischemic stroke compared to warfarin in the ENGAGEAF TIMI 48 trial. $^{75}$ Thus, edoxaban should not be used in patients with a $\mathrm{CrCl}>95 \mathrm{ml} / \mathrm{min}^{.}{ }^{75}$

\section{Conclusion}

In conclusion, $\mathrm{Af}$ is common in patients with ESKD on dialysis and the outcomes of affected patients are poor. While oral anticoagulation using vitamin $\mathrm{K}$ antagonists or direct target oral anticoagulantshas been shown to be efficacious and net beneficial in patients without ESKD, data on their appropriate dosing, efficacy, effectiveness, and safety in patients with ESKD on dialysis are sparse and almost exclusively observational. Given the challenges in making appropriate treatment decisions in patients with ESKD on dialysis 
targeted studies in this population, including randomized trials, are sorely needed and warranted.

\section{Acknowledgement}

The data reported here have been supplied by the United States Renal Data System (USRDS). The interpretation and reporting of these data are the responsibility of the author(s) and in no way should be seen as an official policy or interpretation of the U.S. government.

Disclosure of Funding and Interests: Dr. Winkelmayer was supported by a grant from the NIDDK for studies on atrial fibrillation in ESKD (R01DK095024). Relevant to the topic of this manuscript, he has served as a scientific advisor to Bayer and Daichii-Sankyo, on the event adjudication committee for the Monitoring in Dialysis study (honoraria from Medtronic), and the Steering Committee of the Renal-AF trial (honoraria from the Duke Clinical Research Institute). Drs. Hu and Niu have nothing to disclose.

\section{References}

1. Benjamin EJ, Blaha MJ, Chiuve SE, et al. Heart Disease and Stroke Statistics-2017 Update: A Report From the American Heart Association. Circulation 2017;135:e146-e603. [PubMed: 28122885]

2. Chugh SS, Havmoeller R, Narayanan K, et al. Worldwide epidemiology of atrial fibrillation: a Global Burden of Disease 2010 Study. Circulation 2014;129:837-47. [PubMed: 24345399]

3. January CT, Wann LS, Alpert JS, et al. 2014 AHA/ACC/HRS guideline for the management of patients with atrial fibrillation: a report of the American College of Cardiology/American Heart Association Task Force on Practice Guidelines and the Heart Rhythm Society. J Am Coll Cardiol 2014;64:e1-76. [PubMed: 24685669]

4. Hart RG, Pearce LA, Aguilar MI. Meta-analysis: antithrombotic therapy to prevent stroke in patients who have nonvalvular atrial fibrillation. Ann Intern Med 2007;146:857-67. [PubMed: 17577005]

5. Hogg K, Weitz JI. Blood Coagulation and Anticoagulant, Fibrinolytic, and Antiplatelet Drugs In: Brunton LL, Hilal-Dandan R, Knollmann BC, eds. Goodman \& Gilman's: The Pharmacological Basis of Therapeutics, 13e. New York, NY: McGraw-Hill Education; 2017.

6. Connolly SJ, Ezekowitz MD, Yusuf S, et al. Dabigatran versus warfarin in patients with atrial fibrillation. N Engl J Med 2009;361:1139-51. [PubMed: 19717844]

7. Patel MR, Mahaffey KW, Garg J, et al. Rivaroxaban versus warfarin in nonvalvular atrial fibrillation. N Engl J Med 2011;365:883-91. [PubMed: 21830957]

8. Granger CB, Alexander JH, McMurray JJ, et al. Apixaban versus warfarin in patients with atrial fibrillation. N Engl J Med 2011;365:981-92. [PubMed: 21870978]

9. Giugliano RP, Ruff CT, Braunwald E, et al. Edoxaban versus warfarin in patients with atrial fibrillation. N Engl J Med 2013;369:2093-104. [PubMed: 24251359]

10. US Food and Drug Administration. Andexxa (coagulation factor Xa (recombinant), inactivatedzhzo). (Accessed June 2, 2018, at https://www.fda.gov/downloads/BiologicsBloodVaccines/ CellularGeneTherapyProducts/ApprovedProducts/UCM606687.pdf.)

11. Alonso A, Lopez FL, Matsushita K, et al. Chronic kidney disease is associated with the incidence of atrial fibrillation: the Atherosclerosis Risk in Communities (ARIC) study. Circulation 2011;123:2946-53. [PubMed: 21646496]

12. Shang W, Li L, Huang S, et al. Chronic Kidney Disease and the Risk of New-Onset Atrial Fibrillation: A Meta-Analysis of Prospective Cohort Studies. PLoS One 2016;11:e0155581. [PubMed: 27175779]

13. Liao JN, Chao TF, Liu CJ, et al. Incidence and risk factors for new-onset atrial fibrillation among patients with end-stage renal disease undergoing renal replacement therapy. Kidney Int 2015;87:1209-15. [PubMed: 25587708]

14. Turakhia MP, Blankestijn PJ, Carrero JJ, et al. Chronic kidney disease and arrhythmias: conclusions from a Kidney Disease: Improving Global Outcomes (KDIGO) Controversies Conference. Eur Heart J 2018. 
15. Watanabe H, Watanabe T, Sasaki S, Nagai K, Roden DM, Aizawa Y. Close bidirectional relationship between chronic kidney disease and atrial fibrillation: the Niigata preventive medicine study. Am Heart J 2009;158:629-36. [PubMed: 19781424]

16. Bansal N, Fan D, Hsu CY, Ordonez JD, Marcus GM, Go AS. Incident atrial fibrillation and risk of end-stage renal disease in adults with chronic kidney disease. Circulation 2013;127:56974.

17. Bansal N, Xie D, Tao K, et al. Atrial Fibrillation and Risk of ESRD in Adults with CKD. Clin J Am Soc Nephrol 2016;11:1189-96. [PubMed: 27073197]

18. Piccini JP, Stevens SR, Chang Y, et al. Renal dysfunction as a predictor of stroke and systemic embolism in patients with nonvalvular atrial fibrillation: validation of the R(2)CHADS(2) index in the ROCKET AF (Rivaroxaban Once-daily, oral, direct factor Xa inhibition Compared with vitamin $\mathrm{K}$ antagonism for prevention of stroke and Embolism Trial in Atrial Fibrillation) and ATRIA (AnTicoagulation and Risk factors In Atrial fibrillation) study cohorts. Circulation 2013;127:224-32. [PubMed: 23212720]

19. Zimmerman D, Sood MM, Rigatto C, Holden RM, Hiremath S, Clase CM. Systematic review and meta-analysis of incidence, prevalence and outcomes of atrial fibrillation in patients on dialysis. Nephrol Dial Transplant 2012;27:3816-22. [PubMed: 23114904]

20. Goldstein BA, Arce CM, Hlatky MA, Turakhia M, Setoguchi S, Winkelmayer WC. Trends in the incidence of atrial fibrillation in older patients initiating dialysis in the United States.Circulation 2012;126:2293-301. [PubMed: 23032326]

21. Roy-Chaudhury P, Tumlin JA, Koplan BA, et al. Primary outcomes of the Monitoring in Dialysis Study indicate that clinically significant arrhythmias are common in hemodialysis patients and related to dialytic cycle. Kidney Int 2018;93:941-51. [PubMed: 29395340]

22. Seliger SL, Gillen DL, Longstreth WT,., Kestenbaum B, Stehman-Breen CO. Elevated risk of stroke among patients with end-stage renal disease. Kidney Int 2003;64:603-9. [PubMed: 12846756]

23. Wetmore JB, Ellerbeck EF, Mahnken JD, et al. Atrial fibrillation and risk of stroke in dialysis patients. Ann Epidemiol 2013;23:112-8. [PubMed: 23332588]

24. Airy M, Chang TI, Ding VY, et al. Risk profiles for acute health events after incident atrial fibrillation in patients with end-stage renal disease on hemodialysis. Nephrol Dial Transplant 2017.

25. Yang JY, Lee TC, Montez-Rath ME, et al. Trends in acute nonvariceal upper gastrointestinal bleeding in dialysis patients. J Am Soc Nephrol 2012;23:495-506. [PubMed: 22266666]

26. Bansal VK, Herzog CA, Sarnak MJ, et al. Oral Anticoagulants to Prevent Stroke in Nonvalvular Atrial Fibrillation in Patients With CKD Stage 5D: An NKF-KDOQI Controversies Report. Am J Kidney Dis 2017;70:859-68. [PubMed: 28941763]

27. Herzog CA, Asinger RW, Berger AK, et al. Cardiovascular disease in chronic kidney disease. A clinical update from Kidney Disease: Improving Global Outcomes (KDIGO). Kidney Int 2011;80:572-86. [PubMed: 21750584]

28. Konigsbrugge O, Posch F, Antlanger M, et al. Prevalence of Atrial Fibrillation and Antithrombotic Therapy in Hemodialysis Patients: Cross-Sectional Results of the Vienna InVestigation of AtriaL Fibrillation and Thromboembolism in Patients on HemoDIalysis (VIVALDI).PLoS One 2017;12:e0169400. [PubMed: 28052124]

29. Shah M, Avgil Tsadok M, Jackevicius CA, et al. Warfarin Use and the Risk for Stroke and Bleeding in Patients With Atrial Fibrillation Undergoing Dialysis. Circulation 2014;129:1196203. [PubMed: 24452752]

30. Shen JI, Montez-Rath ME, Lenihan CR, Turakhia MP, Chang TI, Winkelmayer WC. Outcomes After Warfarin Initiation in a Cohort of Hemodialysis Patients With Newly Diagnosed Atrial Fibrillation. Am J Kidney Dis 2015;66:677-88. [PubMed: 26162653]

31. Yang F, Hellyer JA, Than C, et al. Warfarin utilisation and anticoagulation control in patients with atrial fibrillation and chronic kidney disease. Heart 2017;103:818-26. [PubMed: 27852694]

32. US Food and Drug Administration. Eliquis (apixaban) tablets. (Accessed May 28, 2018, at https:// www.accessdata.fda.gov/drugsatfda_docs/label/2014/202155s002lbl.pdf.)

33. US Food and Drug Administration. Xarelto (rivaroxaban) tablets. (Accessed May 28, 2018, at https://www.accessdata.fda.gov/drugsatfda_docs/label/2016/022406s017lbl.pdf.) 
34. De Vriese AS, Caluwe R, Bailleul E, et al. Dose-finding study of rivaroxaban in hemodialysis patients. Am J Kidney Dis 2015;66:91-8. [PubMed: 25804678]

35. Dias C, Moore KT, Murphy J, et al. Pharmacokinetics, Pharmacodynamics, and Safety of SingleDose Rivaroxaban in Chronic Hemodialysis. Am J Nephrol 2016;43:229-36. [PubMed: 27100875]

36. Wang X, Tirucherai G, Marbury TC, et al. Pharmacokinetics, pharmacodynamics, and safety of apixaban in subjects with end-stage renal disease on hemodialysis. J Clin Pharmacol 2016;56:62836. [PubMed: 26331581]

37. Winkelmayer WC, Herzog CA, Montez-Rath ME, Chang TI, Chertow GM. Use of novel oral anticoagulants in patients with end-stage renal disease. Hemodial Int 2015;19:150-3. [PubMed: 25495752]

38. Chan KE, Edelman ER, Wenger JB, Thadhani RI, Maddux FW. Dabigatran and rivaroxaban use in atrial fibrillation patients on hemodialysis. Circulation 2015;131:972-9. [PubMed: 25595139]

39. Chan KE, Giugliano RP, Patel MR, et al. Nonvitamin K Anticoagulant Agents in Patients With Advanced Chronic Kidney Disease or on Dialysis With AF. J Am Coll Cardiol 2016;67:288899.

40. Bonde AN, Lip GY, Kamper AL, et al. Net clinical benefit of antithrombotic therapy in patients with atrial fibrillation and chronic kidney disease: a nationwide observational cohort study. J Am Coll Cardiol 2014;64:2471-82. [PubMed: 25500231]

41. Iseki K, Kinjo K, Kimura Y, Osawa A, Fukiyama K. Evidence for high risk of cerebral hemorrhage in chronic dialysis patients. Kidney Int 1993;44:1086-90. [PubMed: 8264139]

42. Kuo CC, Kuo HW, Lee IM, Lee CT, Yang CY. The risk of upper gastrointestinal bleeding in patients treated with hemodialysis: a population-based cohort study. BMC Nephrol 2013;14:15. [PubMed: 23324652]

43. Phelan PJ, O'Kelly P, Holian J, et al. Warfarin use in hemodialysis patients: what is the risk? Clin Nephrol 2011;75:204-11. [PubMed: 21329630]

44. Potpara TS, Ferro CJ, Lip GYH. Use of oral anticoagulants in patients with atrial fibrillation and renal dysfunction. Nature Reviews Nephrology 2018;14:337. [PubMed: 29578207]

45. United States Renal Data System. 2017 USRDS annual data report: Epidemiology of kidney disease in the United States. National Institutes of Health, National Institute of Diabetes and Digestive and Kidney Diseases, Bethesda, MD, 2017.

46. Kurella Tamura M, Covinsky KE, Chertow GM, Yaffe K, Landefeld CS, McCulloch CE. Functional status of elderly adults before and after initiation of dialysis. N Engl J Med 2009;361:1539-47. [PubMed: 19828531]

47. Johansen KL, Chertow GM, Jin C, Kutner NG. Significance of frailty among dialysis patients. J Am Soc Nephrol 2007;18:2960-7. [PubMed: 17942958]

48. Berger JR, Hedayati SS. Renal replacement therapy in the elderly population. Clin J Am Soc Nephrol 2012;7:1039-46. [PubMed: 22516288]

49. Alem AM, Sherrard DJ, Gillen DL, et al. Increased risk of hip fracture among patients with endstage renal disease. Kidney Int 2000;58:396-9. [PubMed: 10886587]

50. Agarwal S, Bennett D, Smith DJ. Predictors of Warfarin Use in Atrial Fibrillation Patients in the Inpatient Setting. American Journal of Cardiovascular Drugs 2010;10:37-48. [PubMed: 20104933]

51. Winkelmayer WC, Liu J, Setoguchi S, Choudhry NK. Effectiveness and safety of warfarin initiation in older hemodialysis patients with incident atrial fibrillation. Clin J Am Soc Nephrol 2011;6:2662-8. [PubMed: 21959598]

52. Chan KE, Lazarus JM, Thadhani R, Hakim RM. Warfarin use associates with increased risk for stroke in hemodialysis patients with atrial fibrillation. J Am Soc Nephrol 2009;20:2223-33. [PubMed: 19713308]

53. Olesen JB, Lip GY, Kamper AL, et al. Stroke and bleeding in atrial fibrillation with chronic kidney disease. N Engl J Med 2012;367:625-35. [PubMed: 22894575]

54. Limdi NA, Beasley TM, Baird MF, et al. Kidney function influences warfarin responsiveness and hemorrhagic complications. J Am Soc Nephrol 2009;20:912-21. [PubMed: 19225037]

55. Kruger T, Floege J. Vitamin K antagonists: beyond bleeding. Semin Dial 2014;27:37-41. [PubMed: 24400802] 
56. Wizemann V, Tong L, Satayathum S, et al. Atrial fibrillation in hemodialysis patients: clinical features and associations with anticoagulant therapy. Kidney Int 2010;77:1098-106. [PubMed: 20054291]

57. Nigwekar SU, Kroshinsky D, Nazarian RM, et al. Calciphylaxis: risk factors, diagnosis, and treatment. Am J Kidney Dis 2015;66:133-46. [PubMed: 25960299]

58. Brodsky SV. Anticoagulants and acute kidney injury: clinical and pathology considerations. Kidney Res Clin Pract 2014;33:174-80. [PubMed: 26885473]

59. Wright S, Klausner D, Baird B, et al. Timing of dialysis initiation and survival in ESRD. Clin J Am Soc Nephrol 2010;5:1828-35. [PubMed: 20634325]

60. Lau YC, Proietti M, Guiducci E, Blann AD, Lip GYH. Atrial Fibrillation and Thromboembolism in Patients With Chronic Kidney Disease. J Am Coll Cardiol 2016;68:1452-64. [PubMed: 27659468]

61. Chen JJ, Lin LY, Yang YH, Hwang JJ, Chen PC, Lin JL. Anti-platelet or anti-coagulant agent for the prevention of ischemic stroke in patients with end-stage renal disease and atrial fibrillation--a nation-wide database analyses. Int J Cardiol 2014;177:1008-11. [PubMed: 25449515]

62. Tan J, Liu S, Segal JB, Alexander GC, McAdams-DeMarco M. Warfarin use and stroke, bleeding and mortality risk in patients with end stage renal disease and atrial fibrillation: a systematic review and meta-analysis. BMC Nephrol 2016;17:157. [PubMed: 27769175]

63. Van Der Meersch H, De Bacquer D, De Vriese AS. Vitamin K antagonists for stroke prevention in hemodialysis patients with atrial fibrillation: A systematic review and metaanalysis. Am Heart J 2017;184:37-46. [PubMed: 27892885]

64. Harel Z, Chertow GM, Shah PS, et al. Warfarin and the Risk of Stroke and Bleeding in Patients With Atrial Fibrillation Receiving Dialysis: A Systematic Review and Meta-analysis. Can J Cardiol 2017;33:737-46. [PubMed: 28545622]

65. Dahal K, Kunwar S, Rijal J, Schulman P, Lee J. Stroke, Major Bleeding, and Mortality Outcomes in Warfarin Users With Atrial Fibrillation and Chronic Kidney Disease: A MetaAnalysis of Observational Studies. Chest 2016;149:951-9. [PubMed: 26378611]

66. US Food and Drug Administration. Pradaxa (dabigatran) tablets.. (Accessed June 2, 2018, at https://www.accessdata.fda.gov/drugsatfda_docs/label/2015/022512s027lbl.pdf.)

67. Hijazi Z, Hohnloser SH, Oldgren J, et al. Efficacy and safety of dabigatran compared with warfarin in relation to baseline renal function in patients with atrial fibrillation: a RE-LY (Randomized Evaluation of Long-term Anticoagulation Therapy) trial analysis. Circulation 2014;129:961-70. [PubMed: 24323795]

68. Ryan M, Ware K, Qamri Z, et al. Warfarin-related nephropathy is the tip of the iceberg: direct thrombin inhibitor dabigatran induces glomerular hemorrhage with acute kidney injury in rats. Nephrol Dial Transplant 2014;29:2228-34. [PubMed: 24009280]

69. Perzborn E, Roehrig S, Straub A, Kubitza D, Mueck W, Laux V. Rivaroxaban: a new oral factor Xa inhibitor. Arterioscler Thromb Vasc Biol 2010;30:376-81. [PubMed: 20139357]

70. Fox KA, Piccini JP, Wojdyla D, et al. Prevention of stroke and systemic embolism with rivaroxaban compared with warfarin in patients with non-valvular atrial fibrillation and moderate renal impairment. Eur Heart J 2011;32:2387-94. [PubMed: 21873708]

71. Kubitza D, Becka M, Mueck W, et al. Effects of renal impairment on the pharmacokinetics, pharmacodynamics and safety of rivaroxaban, an oral, direct Factor Xa inhibitor. Br J Clin Pharmacol 2010;70:703-12. [PubMed: 21039764]

72. Hohnloser SH, Hijazi Z, Thomas L, et al. Efficacy of apixaban when compared with warfarin in relation to renal function in patients with atrial fibrillation: insights from the ARISTOTLE trial. Eur Heart J 2012;33:2821-30. [PubMed: 22933567]

73. Connolly SJ, Eikelboom J, Joyner C, et al. Apixaban in patients with atrial fibrillation. N Engl J Med 2011;364:806-17. [PubMed: 21309657]

74. Mavrakanas TA, Samer CF, Nessim SJ, Frisch G, Lipman ML. Apixaban Pharmacokinetics at Steady State in Hemodialysis Patients. J Am Soc Nephrol 2017;28:2241-8. [PubMed: 28302754]

75. US Food and Drug Administration. Savaysa (edoxaban) tablets. (Accessed June 3, 2018, at https:// www.accessdata.fda.gov/drugsatfda_docs/label/2015/206316lbl.pdf.) 
76. Parasrampuria DA, Truitt KE. Pharmacokinetics and Pharmacodynamics of Edoxaban, a NonVitamin K Antagonist Oral Anticoagulant that Inhibits Clotting Factor Xa. Clin Pharmacokinet 2016;55:641-55. [PubMed: 26620048]

77. Parasrampuria DA, Marbury T, Matsushima N, et al. Pharmacokinetics, safety, and tolerability of edoxaban in end-stage renal disease subjects undergoing haemodialysis. Thromb Haemost 2015;113:719-27. [PubMed: 25566930] 


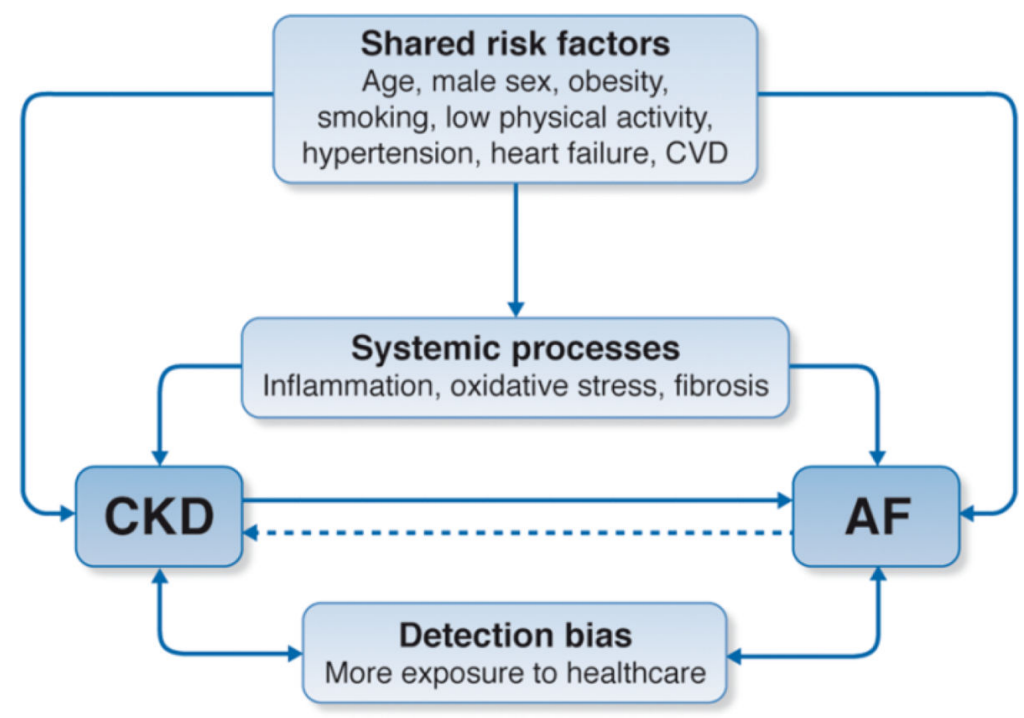

Figure 1: The inter-relationship between chronic kidney disease and atrial fibrillation risk factors.

Note: This figure depicts the inter-relationship between CKD and AF. Both diseases share multiple risk factors, disease states, and pathological processes that can predispose or cause both CKD and AF. Patients with CKD also tend to be more exposed to the health care system, which increases the chances of diagnosing paroxysmal AF and vice-versa. ${ }^{27}$ 


\section{Interval prevalence of oral anticoagulation use by dialysis} modality (July to December 2015)

$35.0 \%$

$30.0 \%$

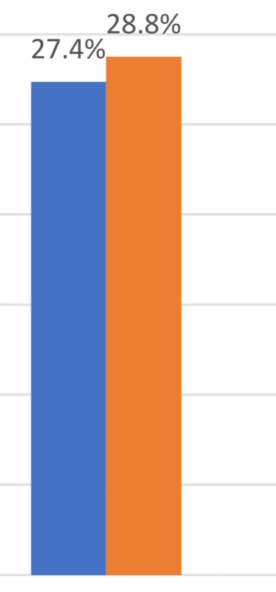

$25.0 \%$

$20.0 \%$

$15.0 \%$

$10.0 \%$

$5.0 \%$

$0.0 \%$

All

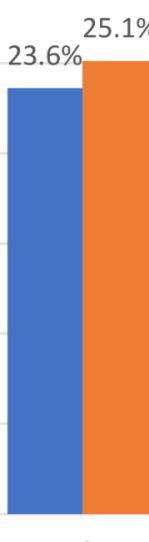

$+2$

Warfarin

Dabigatran

Rivaroxaban

$3.5 \% 3.4 \%$

— HD $\square \mathrm{PD}$

Figure 2: Period prevalence of any oral anticoagulant, or specific agents, between July and December 2015, among patients with ESKD on dialysis, by dialysis modality.

HD - hemodialysis; PD - peritoneal dialysis 


\section{Patterns of Oral Anticoagulant Initiation among Dialysis, by Specific Agent (July to December 2015)}

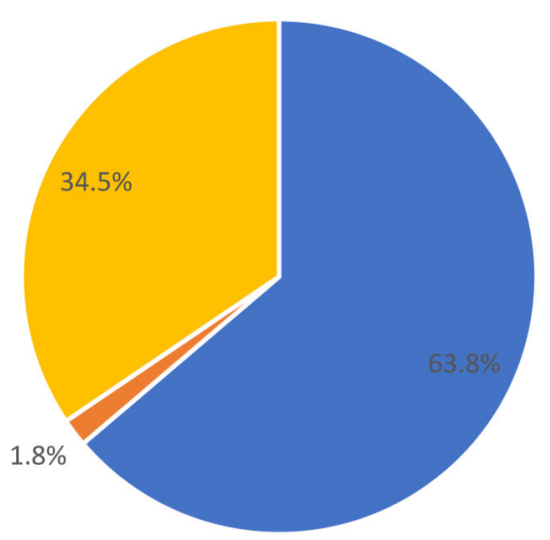

- Warfarin - Rivaroxaban + Dabigatran - Apixaban

New Apixaban Users

$1.7 \%$

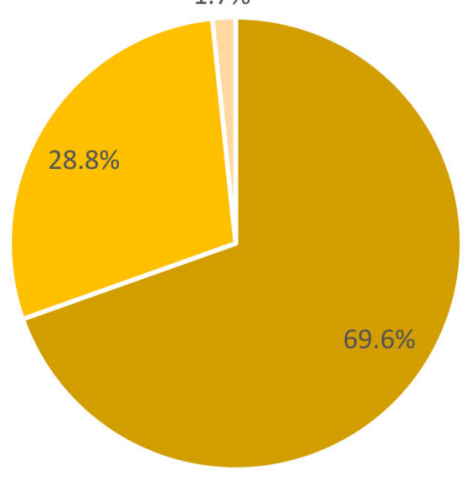

- De Novo Apixaban User

= Switch from Warfarin

" Switch from Dabigatran or Rivaroxaban

\section{New Warfarin Users}

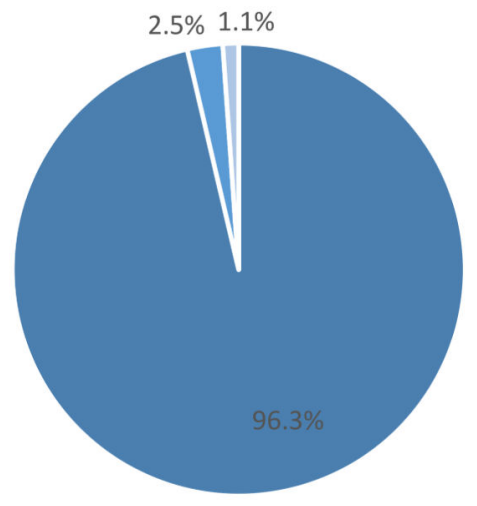

- De Novo Warfarin User

- Switch from Apixaban

- Switch from Dabigatran or Rivaroxaban

Figure 3: Patterns of new initiation of individual oral anticoagulants in patients with ESKD on dialysis, July to December 2015.

Note: All point prevalent patients on dialysis on July 12015 in the USRDS previously diagnosed with atrial fibrillation. Anticoagulation use was assessed between July and December 2015, with new use ascertained by absence of a filled prescription for the same anticoagulant in the previous 6 month period. All patients had Medicare A, B, and D coverage. 
Table 1:

Selected investigations comparing the rates of ischemic and hemorrhage and/or hemorrhagic stroke in ESKD patients on dialysis with AF taking warfarin with non-users.

\begin{tabular}{|c|c|c|c|}
\hline & $\begin{array}{l}\text { Number of ESKD } \\
\text { Patients with AF }\end{array}$ & Findings for Ischemic Stroke & $\begin{array}{l}\text { Findings for Hemorrhage or } \\
\text { Hemorrhagic Stroke }\end{array}$ \\
\hline \multicolumn{4}{|c|}{ Associated with Decreased Rates of Ischemic Stroke } \\
\hline Bonde 2014 & 1,728 & $\begin{array}{l}\text { Subjects with } \mathrm{CHA}_{2} \mathrm{DS} 2-\mathrm{VAsc}>2 \\
\quad \text { VKA user }-4.8(\mathrm{CI}, 6.2-8.5) / 100 \text { person- } \\
\text { years } \\
\quad \text { Non-VKA user }-7.2(\mathrm{CI}, 3.2-6.4) / 100 \\
\text { person-years. } \\
\quad{ }^{\circ} \mathrm{HR}-0.55(\mathrm{CI}, 0.47-0.64)\end{array}$ & $\begin{array}{l}\text { Did not report bleeding rates alone. } \\
\text { Composite of fatal stroke or fatal } \\
\text { bleeding: } \\
\text { - VKA User (low or intermediate risk) } \\
\quad \text { - HR - } 1.32 \text { (CI } 0.74-2.37 \text { ) }\end{array}$ \\
\hline Olesen 2012 & 901 & $\begin{array}{l}\text { Stroke or systemic thromboembolism } \\
\left.\quad{ }^{\circ} \text { HR for VKA use - } 0.44 \text { (CI, } 0.26-0.74\right)\end{array}$ & HR for VKA use $-1.2(\mathrm{Cl}, 0.91-1.77)$ \\
\hline \multirow[t]{2}{*}{ Shen 2015} & 12,284 & VKA user - 2.3/100 person-years. & HR for VKA use - $0.82(0.37-1.81)$ \\
\hline & $(15 \%$ on VKA) & $\begin{array}{l}\text { Non-VKA user }-3.4 / 100 \text { person-years } \\
\quad{ }^{\circ} \mathrm{HR}-0.68(\mathrm{CI}, 0.47-0.99)\end{array}$ & $\begin{array}{l}\text { (Sensitivity analysis, } 2.7 \text {-fold increased } \\
\text { risk of hemorrhagic stroke in VKA } \\
\text { user }^{* *} \text { ) }\end{array}$ \\
\hline \multicolumn{4}{|c|}{ No Associated Change in Rates of Ischemic Stroke } \\
\hline Winkelmayer 2011 & 2313 (new AF) & VKA user - HR 0.92 (CI, 0.61 - 1.37) & $\begin{array}{l}\text { (Hemorrhagic Stroke) } \\
\text { VKA User - HR } 2.38 \text { (CI } 1.15 \text { - 4.96) }\end{array}$ \\
\hline \multirow[t]{2}{*}{ Phelan 2011} & 845 & VKA user - 1.7 / 100 person - years. & VKA user - 10.8 / 100 person-years \\
\hline & $(16.7 \%$ on VKA) & $\begin{array}{l}\text { Non-VKA user }-0.7 / 100 \text { person - years }(p \\
-0.64)\end{array}$ & $\begin{array}{l}\text { VKA Non-user }-8.0 / 100 \text { person-years } \\
(p-0.59)\end{array}$ \\
\hline \multirow[t]{3}{*}{ Shah 2014} & 1626 & VKA User - 3.37 / 100 person-years & VKA User - 10.88 / 100 person-years \\
\hline & & Non-VKA user $-2.91 / 100$ person-years & Non-VKA user - 7.33 / 100 person-years \\
\hline & & $(P=0.44)$ & $\begin{array}{l}\text { HR for hemorrhage - } 1.44 ;(\mathrm{CI}, 1.13- \\
1.85)\end{array}$ \\
\hline \multicolumn{4}{|c|}{ Associated with Increased Rates of Ischemic Stroke } \\
\hline \multirow[t]{2}{*}{ Chan 2009} & 1671 & VKA user - 5.8 strokes / 100 person-years & $\begin{array}{l}\text { (Hemorrhagic stroke) } \\
\text { VKA user - } 1.2 \text { events/100 person-years }\end{array}$ \\
\hline & & $\begin{array}{l}\text { Non-VKA user - } 2.3 \text { strokes / } 100 \text { person - } \\
\text { years }\end{array}$ & $\begin{array}{l}\text { Non-VKA user - } 0.5 \text { events } / 100 \text { person- } \\
\text { years }\end{array}$ \\
\hline Wizemann 2010 & 2188 & $\begin{array}{l}\text { HR } 1.81-\left(95 \% \text { CI, } 1.12-2.92^{*}\right) \\
\text { VKA user - HR 2.17; CI, } 1.04-4.53 \text { (Age > } 75 \\
\text { years) }\end{array}$ & HR $2.22-\left(\mathrm{CI}, 1.01-4.91^{*}\right)$ Not reported \\
\hline
\end{tabular}


Table 2:

Currently FDA Approved Direct Oral Anticoagulant Drugs and Doses Across the Spectrum of Kidney DIsease

\begin{tabular}{|c|c|c|c|c|}
\hline \multicolumn{5}{|c|}{ FDA Approved DOAC Dosing Table for Treatment of Atrial Fibrillation based on Creatinine Clearance } \\
\hline & Dabigatran & Rivaroxaban & Apixaban & Edoxaban \\
\hline \multirow[t]{2}{*}{$\mathrm{CrCl}>90 \mathrm{ml} / \mathrm{min}$} & & $20 \mathrm{mg}$ daily & $5 \mathrm{mg}$ twice daily & Not \\
\hline & $150 \mathrm{mg}$ twice daily & & $2.5 \mathrm{mg}$ twice daily if $>2$ risk factors $*$ & Approved for $\mathrm{CrCl}>95$ \\
\hline $50<\mathrm{CrCl}<90$ & & & & $60 \mathrm{mg}$ daily \\
\hline $30<\mathrm{CrCl}<50$ & & $15 \mathrm{mg}$ daily & & \\
\hline $15<\mathrm{CrCl}<30$ & $75 \mathrm{mg}$ twice daily & & & $30 \mathrm{mg}$ daily \\
\hline $\mathrm{CrCl}<15$ & Not FDA approved & & & \\
\hline Dialysis & Not FDA approved & & & Not FDA Approved \\
\hline \multicolumn{5}{|l|}{ Risk Factors: } \\
\hline \multicolumn{5}{|l|}{- Age $\geq 80$} \\
\hline - Weight $\leq 60$ & & & & \\
\hline - Serum Creatinine & $1.5 \mathrm{mg} / \mathrm{dL}$ & & & \\
\hline
\end{tabular}

